\title{
Health Impacts of Volcanic Activity in Oceania - CORRIGENDUM
}

\section{Joseph Cuthbertson, MPH, MSC, MEH; ${ }^{1}$ Carol Stewart, PhD; ${ }^{2}$ Alison Lyon, MBChB, MS, FRACGP ${ }^{3}$} Penelope Burns, BMed, MPHTM; ${ }^{4}$ Thompson Telepo, BNurs ${ }^{5}$

1. Monash University Disaster Resilience Initiative, Clayton, Melbourne, Victoria, Australia

2. College of Health, Massey University, Palmerston North, Manawatu-Wanganui, New Zealand

3. Western Sydney University, Penrith South, New South Wales, Australia

4. Australian National University, Canberra, Australian Capital Territory, Australia; Western Sydney University, Penrith South, New South Wales, Australia

5. University of Papua New Guinea (UPNG), Port Moresby, Papua New Guinea

Conflicts of interest: none

Keywords: disaster; hazard; health impacts; Oceania; volcano; corrigendum

doi:10.1017/S1049023X20001053

(C) World Association for Disaster and

Emergency Medicine 2020.
https://doi.org/10.1017/S1049023X2000093X, Published by Cambridge University Press, 16 July 2020.

Cuthbertson J, Stewart C, Lyon A, Burns P, Telepo T. Health impacts of volcanic activity in oceania - CORRIGENDUM. Prehosp Disaster Med. 2020;35(5):592-594.

In the original publication of this article, ${ }^{1}$ the outline of the region of Oceania in Figure 1 was slightly out of position. Furthermore, the captions for Figures 3 and 4 were erroneously swapped. The correct versions of all 3 figures with their captions appear below. 


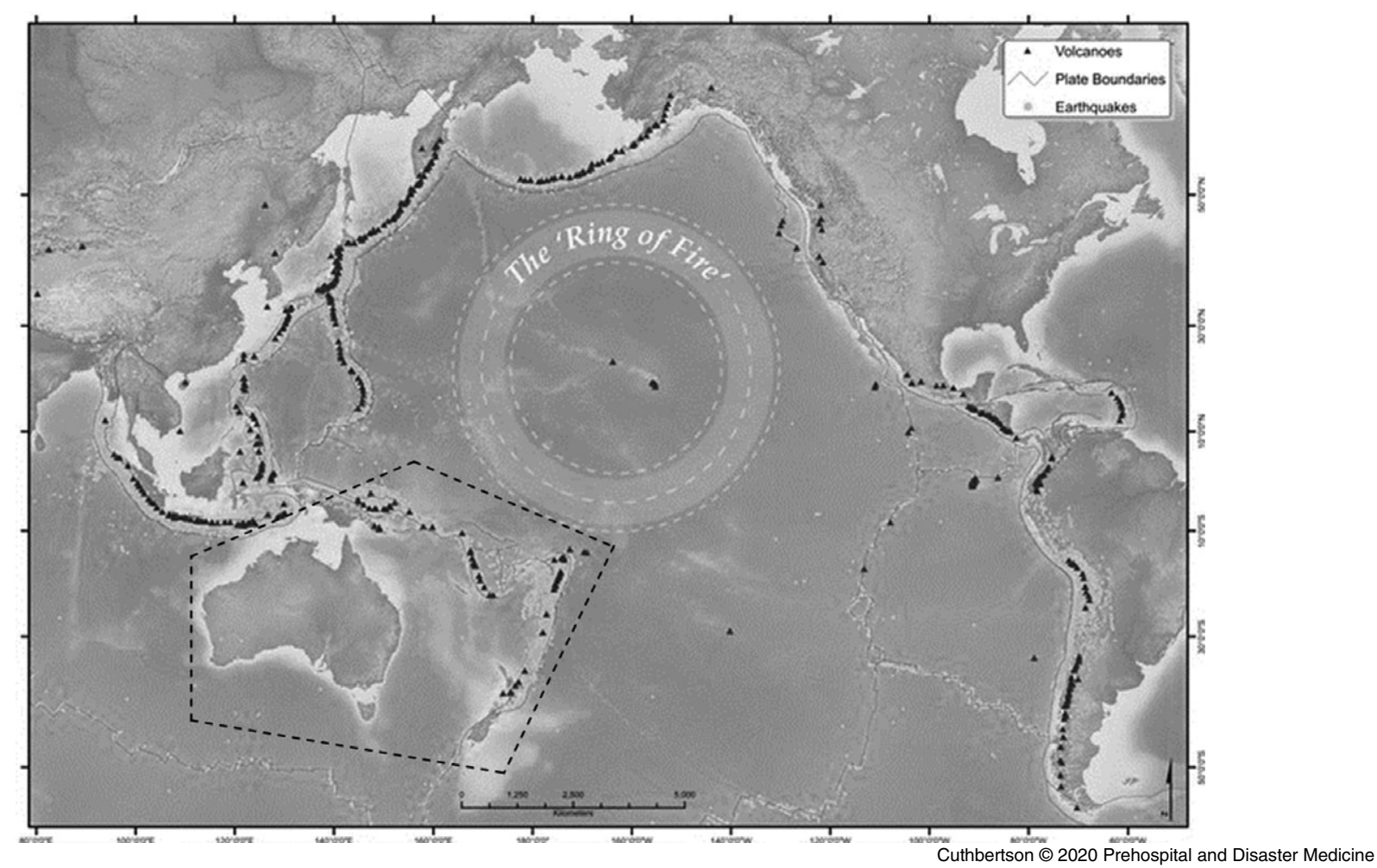

Figure 1. The Pacific Ring of Fire ${ }^{2}$ with Oceania Region Outlined.

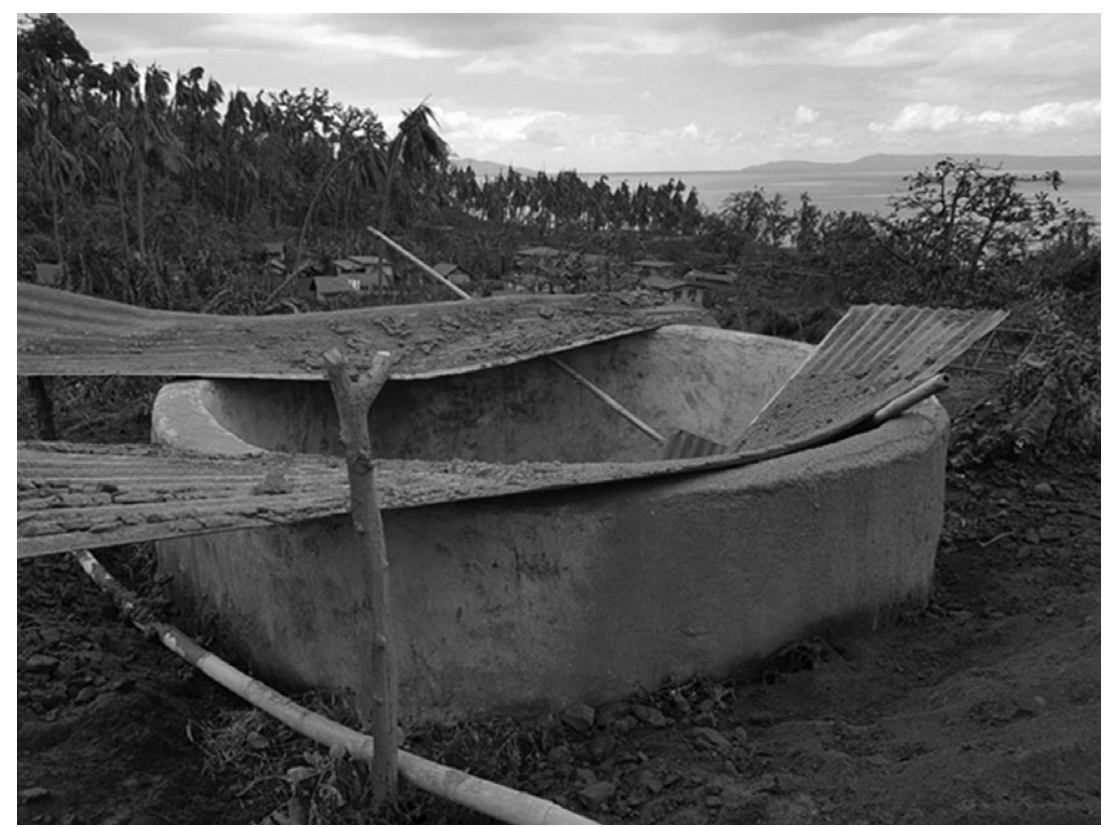

Cuthbertson ( 2020 Prehospital and Disaster Medicine

Figure 3. Village Well Contaminated with Ashfall after Protective Metal Sheets Collapsed, South Ambae. 


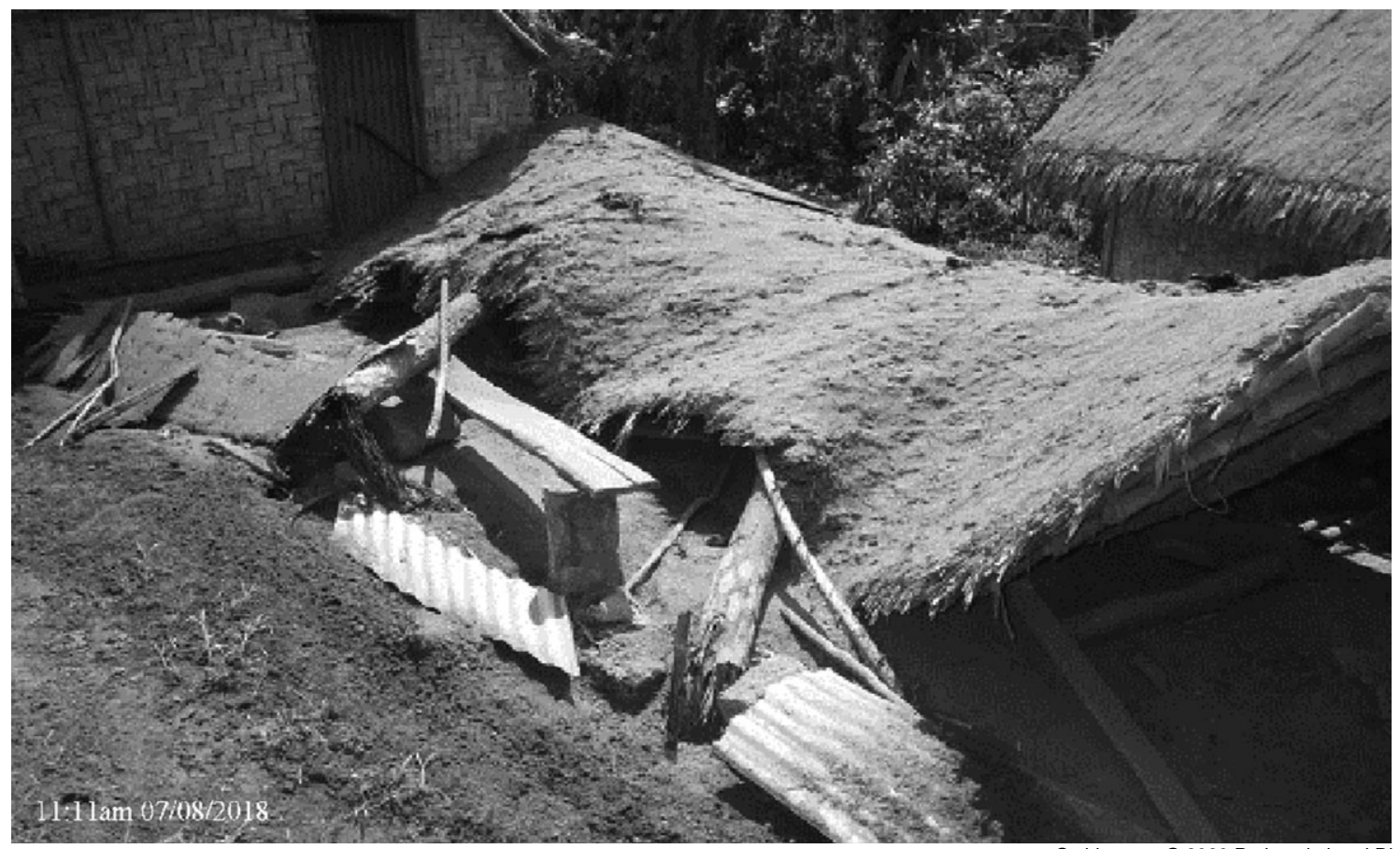

Cuthbertson (c) 2020 Prehospital and Disaster Medicine

Figure 4. Complete Collapse of an Open-Sided Traditional Building ( $55 \mathrm{~mm}$ ashfall depth).

Photo Credit: Susannah Jenkins, Earth Observatory of Singapore.

The authors apologize for these errors.

\section{References}

1. Cuthbertson J, Stewart C, Lyon A, et al. Health impacts of volcanic activity in Oceania. Prehosp Disaster Med. 2020;35(5):574-578.

2. Earth Observatory of Singapore. Singapore: Asian School of the Environment. https:// www.earthobservatory.sg/resources/maps/ring-fire. Accessed February 11, 2020. 